\title{
Tourism and Sport: Strategic Synergies to Enhance the Sustainable Development of a Local Context
}

Authors' contribution:

A) conception and design of the study

B) acquisition of data

C) analysis and interpretation of data

D) manuscript preparation

E) obtaining funding

\section{Elena Radicchi}

University of Florence, Italy

ABSTRACT

In recent years sport has become a phenomenon of large dimensions and it is an important resource for the development of a local context (Hautbois, Desbordes, 2008; Maier, Weber, 1993; Weed, Bull, 2004). The combination of physical and sports practices within a natural environment (outdoor) broadens the range of activities that people can choose in their free time (nordic walking, hiking, rediscovering rural districts, walking and cycling in urban spaces, etc.). The demand of this kind of activities is continuously evolving. Sports tourism is a new opportunity for the development of tourism offer. Cities, regions, rural areas, etc. through the exploitation of local resources, vocations and specializations can promote a destination in terms of reputation and tourism flows.

This research aims to stimulate a reflection on the role that the synergies between tourism and sport, combined with the use of resources, services and local products (cultural and artistic paths, local artefacts, wine tastings, etc.) may have for the development of a specific territory and its socio-economic environment.

KEYWORDS $\quad$ sport, tourism, sustainable development, local context

\section{Introduction}

In recent years, sport has become a phenomenon of large dimensions and it is an important resource for the development of a local context (Hautbois \& Desbordes, 2008; Maier \& Weber, 1993; Weed \& Bull, 2004). The combination of physical and sports practices within a natural environment (outdoor) broadens the range of activities that people can choose in their free time (Nordic walking, hiking, rediscovering rural districts, walking and cycling in urban spaces, etc.). The demand for these kinds of activities is continuously evolving.

Over the last few years, the concept of "who" wants to travel has changed. Moreover, a redefinition of "why" and "how" people want to make a journey has occurred. Intrinsic motivations to travel are increasing in importance, such as the desire of discovery, self-realization, and socialization, compared to traditional factors like relaxation and entertainment (Nordin, 2005). These motivations on one hand induce tourists to search "unconventional, involving and authentic experiences," and on the other hand, they inspire new types of tourism activities: creative and cultural tourism, food and wine tourism, wellness tourism, sports tourism. 
Sports tourism is a new opportunity for the development of tourism. Through the exploitation of local resources, vocations, and specializations, cities, regions, rural areas, etc., can promote a destination in terms of reputation and tourism flows.

This research aims to stimulate reflection on the role that the synergies between tourism and sport, combined with the use of resources, services and local products (cultural and artistic paths, local artifacts, wine tastings, etc.) may have for the development of a specific territory and its socio-economic environment.

The paper is based on the analysis of the tourism industry $(\S .2,2.1)$, the new demand for "experiential tourism" (§. 3), and a literature review on sports tourism $(\S .4,4.1)$. The research is supported and integrated with a variety of data and national surveys. Empirical cases related to different sports and territories are also presented in order to encourage the understanding of this complex phenomenon.

The flow of tourists related to sports activities and events can foster the development of a specific area in a "sustainable" way: the tourism environment is seen in a holistic sense; it is composed not only by natural, historical and architectural resources, but also by the human capital embedded in the local context. The development of sports tourism involves a territory and its surrounding environment, opening up spaces for the development of services offered through economic activities that can sustain their local economy and be developed (rural B\&B, agencies and tour operators specialized in sport, sports tourism managers, etc.).

The activation of the virtuous circle between tourism, sport and territory, implies a strategic orientation shared by the main stakeholders (national institutions, agencies for the regional promotion, etc.). They should be involved in the implementation of a local development policy in order to enhance the access, the usability, and the tourist attractiveness of a place.

\section{The tourism industry}

Tourism is an economic sector widely studied from different points of view. Many definitions are used to capture the essence of the tourism sector. These are usually also significantly different, depending on the disciplinary perspective that framed the analysis, as regard to the size of tourism feasibility (infrastructure, transportation, hospitality, etc.).

In 1982 the "Tourism Society" identified two essential elements in order to define tourism activities:

- a temporary short term movement towards "destinations" other than the habitual place of residence and work;

- activities that are carried out by people during their stay in a destination, for any reason.

In statistical terms, tourism is defined as

"The movement of people who leave their habitual residence and work place to different locations with multiple goals that may include: leisure, culture, health, work or other reasons.

In this context, the tourist is he (or she) who spends at least one night away from home" (Istat).

This definition is useful for defining effective indicators that allow for the study of the flow of arrivals and presences. Nevertheless, it appears rather limited in terms of providing enlightenment for the specific characteristics of the sport tourism sector. In particular, the need for an overnight stay outside the place of residence to engage in tourism appears quite restrictive. For example, under this definition, even a person who takes the train, goes to the Cinque Terre to go trekking and takes the train back once finished the trek, can be considered a "sports tourist".

In 1993 the UNWTO (United Nations World Tourism Organization) defined tourism as "the activities of people who travel and live in places different from their usual environment for not more than one consecutive year, for leisure, business and other purposes".

Like the former, the UNWTO's definition highlights that the concept of tourism frames the trip above all and therefore the activities that are performed within the "destination". Whatever is the reason for the trip; tourists consume services (e.g., hotel, catering, etc.) or use the facilities available on the territory or those necessary to reach it. 
In recent decades, tourism has gained important rhythms of development. Reasons for this are many, including those that can push people to leave their place of residence, as well as the gradual increase in the number of travel-related services and the efficiency and diffusion of the latter.

Especially since the late 1970's, the acceleration of tourism has increased. This primarily concerns business tourism, as a result of the increasing globalization of the economy and the opening up of markets ${ }^{1}$. Although business tourism is a catalyst for the development of the tourism system, other forms of tourism showed a significant acceleration over past decades, by renewing the sector (cf. §. 2.1). People see tourism as a significant response to their perceived needs. They abandoned the concept of tourism as an exclusive expression of relax and recreation. Contemporary people seem to express new needs that lead them to travel often, especially when they do it out of choice rather than strictly for work. Through the journey they satisfy their need of "being in the know." They change the quality of their life, increasing their psychological space and proposing new goals, such as meeting different people, and discovering new places and cultures.

\subsection{The effect of tourism on the global economy}

Tourism is an economic activity able to globally create growth and employment, while contributing to

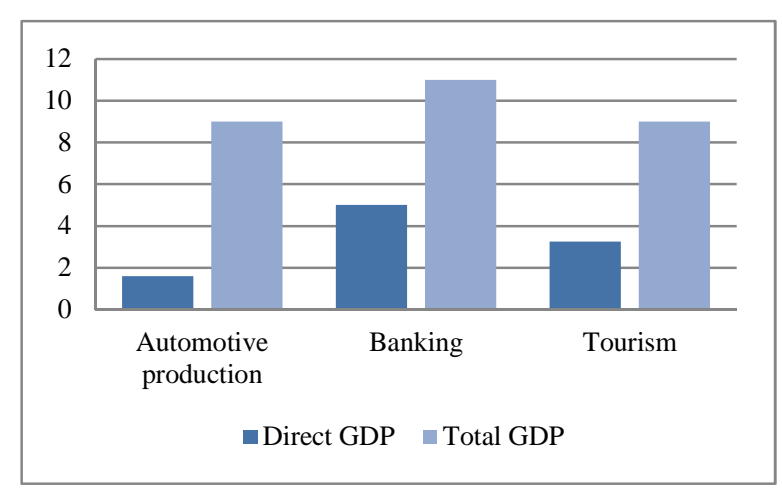

Figure 1. Contribution to the global Gross Domestic Product by industry, 2011

Spurce: WTTF, 2012.

this regard, if we look at the past decade's trend, employment growth in the tourism sector has been almost always higher than the rest of the economy.

In the past 15 years, tourism has experienced a very rapid and intense expansion. In the mid-1990s global tourist arrivals were equal to 528 million units, while in 2005 they totaled 753 million units (see Figure 2). Until the beginning of the new millennium, economic development and income growth have contributed to the increase not only of the number of tourists, but also to their spending. Between 2000 and 2002 there has been an interruption in the development and economic and social integration of rural and mountain areas, coastal regions and islands, peripheral regions, ultra-peripheral or convergent regions. The global tourism industry generates nearly $9 \%$ of international GDP (Figure 1) and more than 5\% of EU GDP, a percentage that is steadily increasing (Eurostat, 2010). Tourism in Europe is the third major socioeconomic activity after the trading, distribution and construction sectors. If we consider all the economic activities related to the tourism industry ${ }^{2}$, the contribution of tourism to the Gross Domestic Product is even higher: it contributes to more than $10 \%$ of EU GDP and it provides about $12 \%$ of the total employment. In

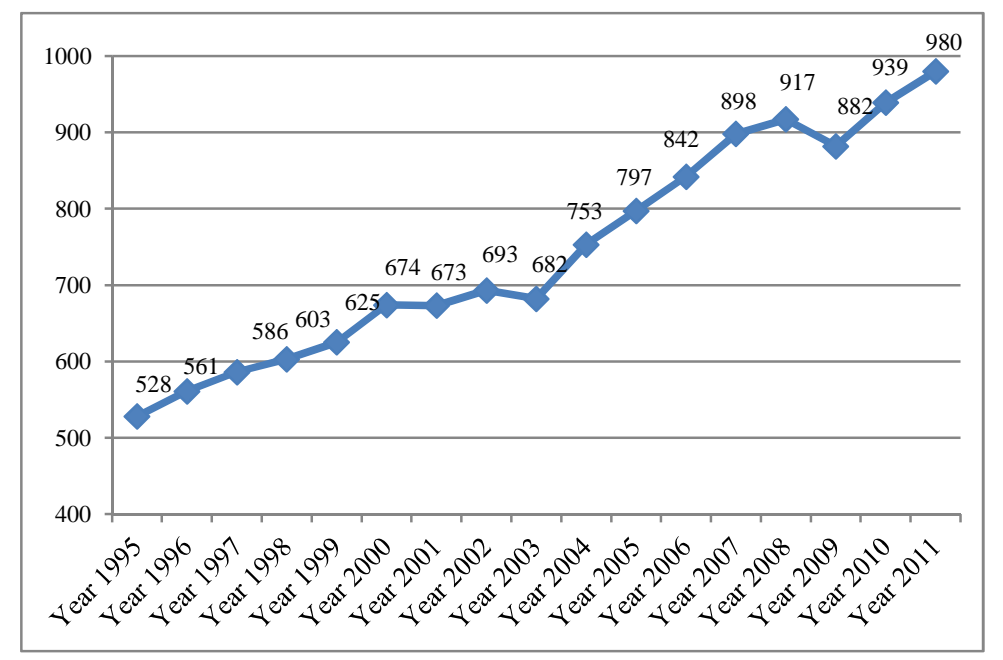

Figure 2. Trends in international tourists flows (1995-2011) (mln) Source: UNWTO, 2012.

\footnotetext{
${ }^{1}$ Over the past few years the business travel segment has seen a slight drop: in 2011 only $15 \%$ is related to business. Companies, even in the light of international crisis, often react by containing the costs related to this budget item by using new technologies (video conferences, e-mail, etc.).

${ }^{2}$ Consider for example the fields of construction, distribution, transport companies (aviation, maritime, railway, bus, etc.) and cultural industries.
} 
this growth due to the consequences of the terrorist attacks of September 11, 2001, and the SARS epidemic broke out in Asia in 2002, in addition to the mediocre performance of most of the world's economies.

According to the WTO, the phase that has seen the decrease of international tourist mobility in the past two years, mainly due to global economic crisis, seems to be over. Despite the lower availability of credit, increasing unemployment, political tensions and natural disasters in various parts of the world, people seem to forget quickly. In 2011 there were 980 million visitors worldwide (Figure 2) and the forecast for 2012 sees an increase that comes close to $4 \%$ compared to the previous year.

Europe was the world's main tourism destination until the late 1990s, over the past two years, a wide

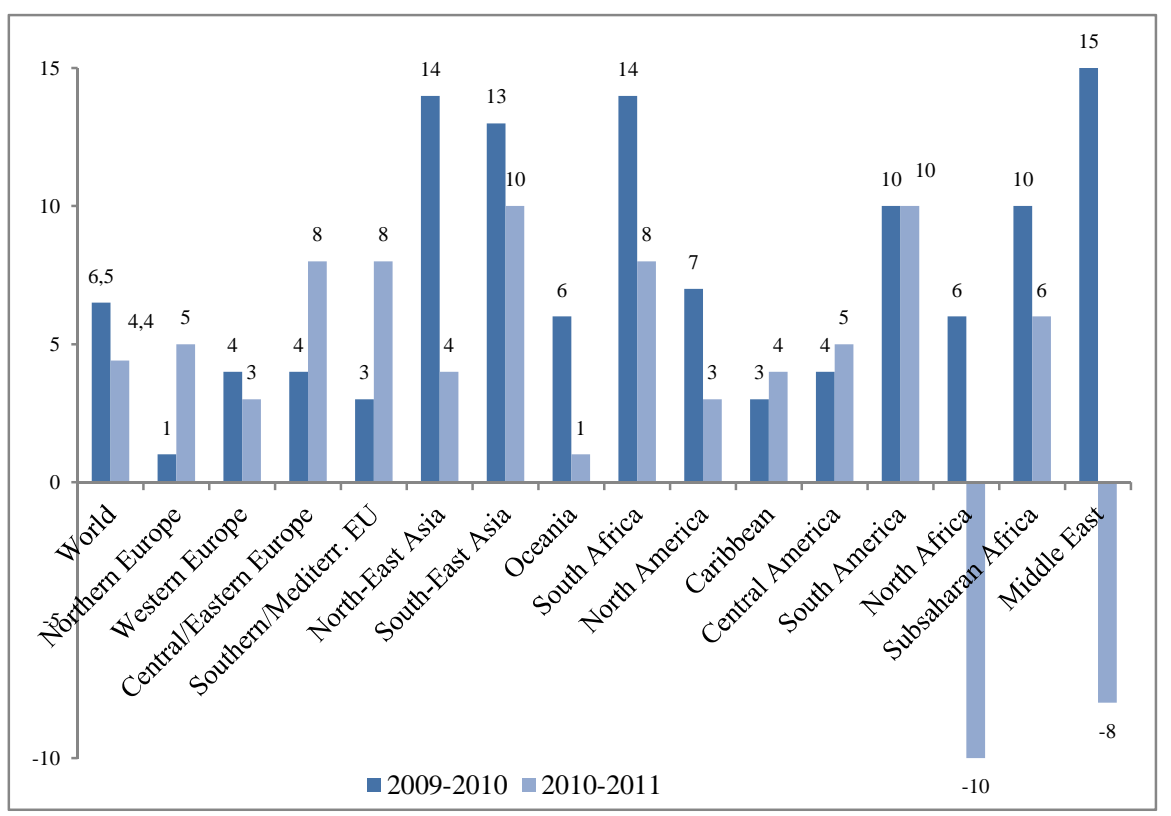

Figure 3. Tourists flows by geographical area. Years 2009/2010 and 2010/2011 Source: WTO, 2012. variety of tourist destinations such as Asia, Africa and the Middle East emerged (Figure 3). However, Asia slowed its growth in the first two months of 2011 compared to 2010 . The results are better than expected for Europe, driven by the recovery of Central and Eastern Europe countries that have provided an increase in the number of travelers to the countries of the South and the Mediterranean such as Spain and Portugal.

This phenomenon is due in part to exogenous factors: Europe has indeed benefited from a share of tourist mobility originally directed toward the countries of North Africa and the Middle East, destinations strongly penalized by the political evolution of the North Africa and the Middle East countries, which have respectively recorded a decrease in tourism demand of $9 \%$ and $10 \%$ (WTO, 2012).

In 2011, according to the World Tourism Organization, more than 50\% of tourists were travelling for leisure, entertainment, and holidays. Although in the past two years the leisure sector has suffered the effects of the global crisis, people have not given up completely on going on holiday. Rather, they have changed the way they organize their travel, for example by using new media channels, by selecting economic and easily accessible destinations, at home or abroad, by travelling by their own means of transport or with low-cost flights, and perhaps by reducing the number of days of vacations.

\section{The new demand of tourism: emotional and experiential dimensions}

For a correct analysis of the tourism phenomenon we should clear up the needs and attitudes expressed by travelers. If on one hand, the classification of reasons to travel proposed by the WTO (see §. 2.1) is useful in giving a rough idea of the desires and needs that drive people to travel, the classification does not seem sufficient enough to explain or to deeply understand the factors that underlie the different choices of people. To give a thorough answer to questions like "who is the tourist?", "why does he move?", "what kind of experience is he searching for?", "what does he need?", we should consider several aspects which affect the different choices (Apostolopoulos, Leivadi, \& Yannakis, 1996):

- cultural (culture, type of study, social status, etc.),

- social (peer groups, family role, status, etc.),

- personal (age, occupation, economic conditions, lifestyle, personality, self-esteem, etc.),

- psychological (motivation, perception, learning, opinions, attitudes, etc.). 
Although the motivation to travel is variable in different contexts and cultures, it is difficult to identify the element that distinguishes one tourist from another. In the field of tourism psychology, Crompton (1979) has grouped the factors that push people to go on vacation into two macro-categories:

- push factors (push), that explain the desire to travel,

- factors of attraction (pull), that explain the choice of destination.

According to this classification, in choosing a vacation, two different aspects come into play and sometimes in conflict:

- psycho-social (emotional, social, cognitive and motivational), where the author identifies seven motivations to travel:

- escape from daily life and its environment,

- exploration and evaluation of themselves,

- physical and mental relaxation,

- prestige,

- regression to forms of infantile or adolescent behavior,

- improving and strengthening family relationships and friendship,

- facilitation of social interactions.

- "tangibles", referring to the economic possibilities and cultural and geographical elements of the holiday.

These issues affect one another in the selection process of a vacation. Push factors are sociopsychological in nature and are related to the inner needs of an individual. Among these, the main factor seems to be the desire to "escape" from stress and daily constraints. This factor is also linked to the search for "recognition," that is, the desire to raise one's own personal status.

Pull factors refer instead to the attractive elements of a particular destination. These are usually evident in those tourists who carefully select their holiday and travel destinations, and are attentive to intermediate stages such as possible opportunities for inner enrichment (the main goal for this type of tourist are the pursuit of novelty and the desire to enrich their knowledge).

There are many reasons for tourism from an anthropological and psychoanalytical point of view. If the tourist is primarily seen as a participant in a kind of "collective ritual", unaware of the deeper meaning inherent in it, then, following the psychoanalytical approach, tourism is rather seen as an activity designed to meet a variety of needs and unconscious tensions.

According to Dall'Ara (1990), motivations to travel can be gathered in three distinct areas:

- the area of "the self", where the choice of travel is dictated by the need to restore the physical and mental equilibrium of the individual,

- the area of the "other self", where the pursuit of transgression, and "otherness" are among the main factors of choice,

- the area of the "inside", where the journey, often in distant and isolated places, has the goal of finding a deep contact with the inner life of an individual.

In order to find the reasons that usually push tourists to a particular travel choice, many authors agree that the "escape" from everyday life and from problems that society inflicts is a recurring element in the choice of trip. In this case, the holiday fulfils the role of compensation as regards to some needs and deficiencies felt in everyday life (sun, sea, relaxation, fun, etc.). Alternatively, it becomes a way to reward people for their work done during the year: through this choice each person looks for distinguishing themselves from others. Finally, it is useful to point out that, often, the motivation to travel also depends on the type of vacation chosen. Consider for instance some reasons that generally are related to certain types of tourism:

- physiological: health and wellness tourism, sports tourism,

- escape: escape from everyday life tourism, 
- interpersonal: social tourism, to spend time with family and friends or to search new relationships,psychological: tourism for relaxation, fun, etc.,

- cultural: cultural, historical, artistic tourism, etc.,

- environmental: tourism "en plein air", ecotourism, etc.,

- status: elite tourism, for people of the same social class or higher class,

- exploratory: adventure tourism, hiking, etc.

"The tourist's needs derive from the necessity that people occasionally feel of escaping from ordinary life, so as to create a discontinuity sufficiently perceptible compared to the everyday routine, and a reasonable doubt regarding the prospect of return" (Brunetti, 1999).

By focusing only on tourism or vacation tout court, the reasons for travelling are mainly connected to the use of leisure time. In this sense, these motivations can be divided into two classes:

- leisure motives or desires, occurring in the search of fun, entertainment, and relaxation,

- cultural motives or desires, occurring in the search of knowledge, learning, novelty.

In brief, we can say that tourist behavior arises from numerous needs that are observable in the

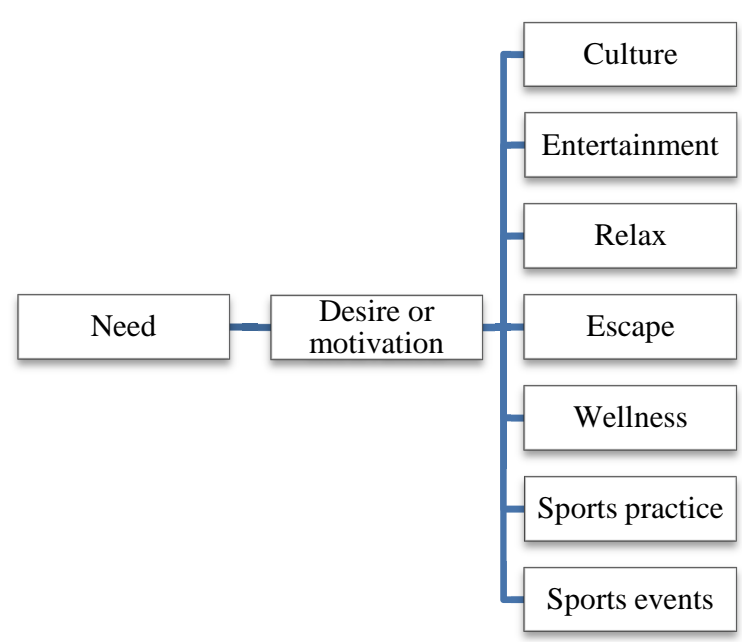

Figure 4. Tourists needs and reasons for travelling Source: Adapted from Forlani, 2005. necessity of a temporary existential balance for people that are willing to invest resources, energies and money to travel (Figure 4).

The proliferation of sport vacations has received particular attention from social science experts that connect the development of sports tourism in what two well-known sociologists, Elias and Dunning (1989), called "quest for excitement". Through these forms of travelling, people stir emotions, pleasures often missing in their daily lives and that are sought after even for brief and limited periods of time, as a moment of escape from stress and daily routine.

In contemporary society, sports tourism is an appealing and feasible opportunity, it allows people to relax and have fun in a socially acceptable and economically accessible manner. Sports tourism can definitely strengthen individual self-esteem and sustain a sophisticated "game" based on the alternation of physical effort and relaxation.

The sports tourism industry makes it possible to exploit these opportunities, by configuring an appropriate offer for such purposes and giving the visitor/customer the illusion of the adventure and the experience (Hallman et al., 2012). However, the uncertainty of the adventure and the real risks remain limited or basically under control.

Another important element that helps to clarify the cultural significance of sport tourism is linked to the so-called progressive "sportivisation" of our society as a whole (Russo, 2004). More and more people practice sports all year-round. For these people, sport is a way of life, and it is not usually chosen and organized by being a member of sports associations, federations, fitness centers, etc. The development and renewal of sports, the new hedonistic way of using sports as pleasure, and the focus on nature have favored the development of a positive image of sport as a fundamental activity of loisir (Varaldo, 2002).

Leisure time is as a "scarce resource" (Resciniti, 2002) that people want to use actively, without wasting it. Therefore, people are often looking for activities that can provide leisure, entertainment, relaxation, and sports experiences.

A growing number of people are aware of the importance of being healthy, pursuing an active lifestyle, continuously exercising throughout the year, and often increasing their workout activities during 
periods of vacation. However, there are also people who find it difficult to practice sports in their daily lives, and so they await the opportunity offered by a holiday. Moreover, professional athletes as well as some amateurs keep training even during their vacations and choose specific locations in order to improve their physical condition. Retreats, training periods, etc., are often held in pleasant vacation spots, appropriate for specific sports performance needs (Walker, Hinch, \& Higham, 2010). Consider for example Olympic windsurfers who choose coastal resorts at different times of the year where they can find the right "waves" or footballers who, during their summer athletic preparation retreats before the kick-off of the Championship spend their time in a climate and environment favorable to athletic performance.

Sport and tourism are closely linked and positively affected by the global spread of new lifestyles and consumption. The passion for a "unique" experience, the taste for "adventure vacations" and the acknowledgement of sports training as an important process in health protection, for which tourism can serve as a catalyst, are important ingredients of contemporary lifestyle.

In recent years, we have witnessed a transformation in the way people enjoy tourism, even in the light of numerous elements that characterize the contemporary tourist phenomenon. In particular, an explosion of the tourist experience in a multiplicity of forms has emerged: the user is searching for an "authentic" tourism experience, where qualifying aspects are represented by the bond with the territory, and thus with the culture, traditions, typical products, and local resources. Such transformations in tourism consumption patterns determine significant effects on the whole system offering. "Tourist products" (Tamma, 2002) seem to assume the form of "emotional experience goods" (Pencarelli \& Forlani, 2002). These considerations indicate that sport, an "experience provider" par excellence (Radicchi \& Zagnoli, 2008), may represent a significant element within the overall tourist experience that a particular territory can offer, even in order to promote it as a tourist destination.

\section{A definition of sports tourism}

Sports tourism is one of the most dynamic sectors of the contemporary leisure industry and it is a very important socio-cultural and economic phenomenon. This segment combines elements of tourism and sport by offering a wide variety of activities dedicated to different target groups (children, women, youth, seniors, etc.). There are various reasons for this diffusion. Sports tourism integrates the physical, emotional, and social opportunities offered by sports by combining them with cultural experiences, the taste for risk and adventure, opportunities for knowledge, and the discovery of new things (people, landscapes, colors, smells). These are dimensions that can be researched, experienced, and tested during trips to both "faraway places" and places that are simply different than the usual ones.

To understand the phenomenon of sports tourism it is essential to analyze its links with:

1. Sport;

2. Tourism in the broadest sense, and at the same time the peculiarity of this combination.

The first official reflections about the relationship between sport and tourism date back to 1971. They fall within the framework of congressional and seminar activities of the International Council for Sport Science and Physical Education (ICSSPE). The first scientific publication that includes the sports tourism theme, the "Journal of Sports Tourism", dates back to 1983, when the first World Conference on this topic was jointly organized by the World Tourism Organization (WTO) and the International Olympic Committee in 2003 in Barcelona. The theories proposed on this topic do not provide an unambiguous definition of this phenomenon, even because of the recent interest expressed by scholars. We found several definitions used to capture the essence of this segment and they may significantly differ depending on the scientific perspective adopted as regards to the practical problems faced by those who have attempted to develop a classification of sport tourism.

An early definition was proposed by Pigeassou (1997) who classifies sports tourism based on two factors: destination and type of activity. According to the author's point of view, we can speak about sports tourism only when the movement, the destination, and the way of vacationing are functional and dependent 
on the participation of typical phenomena of sports culture: an expression of physical activity (practice), and/or cultural events (exhibitions, conferences, sporting events).

Gibson (1998) defines the sports tourism as set of

"leisure-based trips that bring individuals temporarily outside their local community in order to participate actively in sports, or as spectators of sports or sports-based events".

Standeven and De Knop (1999) define this phenomenon as

"any form of activity or passive involvement in sport activities, carried out randomly or organized for non-commercial or commercial reasons, which require leaving the home or place of work".

Another possible definition of sports tourism is

"the set of journeys that lead people for more or less long time periods away from their places of residence in order to practice competitive or simply amateur sport activities or to participate in sports events as spectators, fans, and supporters. The sports practice or the sports event may be the main reason for the journey, or at least be an important motivation that drives people to travel" (Varaldo, 1999).

Nevertheless, any difference among sport tourism activities carried out for leisure does not emerge from these definitions, and this is also true of amateur or the professional activities of athletes, teams, and coaches. These definitions also reveal a direct connection with practiced and spectator sports. However it is not easy to define the conceptual perimeter of sports tourism, since even the concept of sport may include a beach volleyball match, a walk in the mountains, a horse ride, a bike ride, the final race of the Olympic Games, a chess match, etc.

An initial typology of sports tourism is based on the criterion of the purpose of the trip, such as travels aimed at:

- the practice of competitive or recreational sport,

- the collaboration in planning, organizing, and realization of sporting events and activities,

- attending sporting events.

Based on this classification it is possible to affirm that sports tourism may be more or less active or passive, at least from the point of view of physical activity that it is associated with.

Active sports tourism includes:

- holiday/trips where sport is the main motivation of the trip both for leisure purposes which, in turn, can be grouped as:

- holidays/trips where just one sporting activity is practiced,

- holidays/trips characterized by various sports which have a great importance within the overall vacation experience,

- sporting activities as part of holidays where sport is one of the reasons, but it is not the main element. There may be random participation during the holiday (e.g., competitive matches of beach volleyball, windsurfing courses or individual lessons, etc.), or sports activities carried out independently.

In addition to this general typology of segmentation, sports tourists can be differentiated on the basis of other dimensions:

- the duration of the visit,

- the frequency of use,

- the costs incurred,

- the means of transport used for the trip.

In passive sports tourism, sport is the main reason of the journey for people who fulfill the role of spectators and supporters while attending sporting events. In this case the term "passive" can be misleading: some spectators are indeed "experts", they read in advance about the event and they feel very strongly involved. Other spectators plan their holidays and their trip around participating in a sporting event several 
years in advance and stay "in group" at the event venue by sharing the emotions offered by the match with other supporters.

Even the organization of fan groups to attend football matches is an important phenomenon that can be included within the sports tourism sector. Moreover, it is a "real business" that can generate tens of millions of Euros (Econstat, 2008). Even in this case, beside tourists that mainly travel to attend the sports event, we can also find casual spectators: those who do not plan to travel to attend a sporting event, but they just occasionally decide to attend the match after finding information and advertising campaigns in a tourist destination.

We can even mention another segment of tourists not considered sportive tout court: people attracted by the promotion of a tourist destination that has become well known through sports events. Valencia is an example, it is a city which, after the America's Cup in 2007, has become an urban pole of attraction for sports and culture, not only at national level ${ }^{3}$.

\subsection{Sports tourism: emerging trends}

Sports tourism does not find a specific conceptual setting and it is placed within the "leisure,

\begin{tabular}{|l|l|}
\hline & \\
\hline & \\
- Leisure, recreation and holidays & $\square$ VFR, health, religion and other \\
- Business and professional & $\square$ Not specified
\end{tabular}

Figure 5. Main motivations that push people to travel

Source: WTO, 2012 recreation and holidays" category (Figure 5). Sport tourism is a "niche" segment, although the practice of sporting activities has become an essential element of contemporary holiday motivations due to its recreational, aesthetic, and healthy features. The flows of tourists characterized by strong motivation for a period of stay by combining the experience of sport and discovering the relationship with a territory are continually growing and changing. The holiday, especially when it is "active", combines a traditional stay with physical and sports activities such as golf, tennis, trekking, Nordic walking, cycling, canoeing, sailing, equestrian sports, rafting, gastronomic tasting, etc.

In 2010, sports tourism at the international level generated an added value of more than 120 billion dollars and an annual growth rate of $10 \%$ until 2020 is estimated (WTO, 2011).

In Italy, over 10 million trips are made for sports tourism reasons. The turnover of this sector is estimated at 6.3 billion Euros and about 1.5 billion results from spending on "plein air" sports such as sailing, canoeing, diving, etc. (BTS, 2011).

According to the latest survey on emerging trends in tourism carried out by ISTAT in 2011, although in the last four years this sector has registered a steady decline in the number of trips by Italians, both nationally and internationally, the main motivation to travel is still pleasure and leisure $(69.9 \%)$ and within this category the so-called sport vacation reaches $8 \%$ of people's choices.

\footnotetext{
${ }^{3}$ This is a marketing phenomenon analyzed and investigated in the paper by Radicchi E., "Megaeventos deportivos y creación de valor para las economías anfitrionas" [Major Sports Events and value creation for the host economy], in Llopis Goig R. (eds), Megaeventos Deportivos. Perspectivas Científicas y Estudios de Caso, [Major Sports Events. Scientific Perspectives and Case Studies], Editorial UOC, Barcelona, pp. 25-51, 2012.
} 
As regards to the weight of this phenomenon, the latest figures available from Econstat within the framework of the "Observatory on sports tourism" in Italy, show that this segment each year registers 2.8 million travelers that move for sports practice and/or to attend sporting events, with an average stay of 6 days.

In 2008, the total expenditure was about 6.3 billion Euros (589 euro on average per trip, 105 Euros per night). In terms of average expenditure, the most expensive travels are those related to water sports (935 Euros), such as sailing, canoeing and diving, while the total expenditure is much larger for winter sports (downhill skiing, cross-country skiing, snowboarding), accounting for approximately $26 \%$ of the whole. Soccer and other outdoor activities such as cycling, golf, running, athletics, fishing, and hunting follow in this ranking.

In $73 \%$ of trips, the goal is amateur and recreational sport practice, in $16 \%$ of cases, the goal is to attend the events, while in $11 \%$ of journeys people travel to be with family members engaged in active sports. In 2008, $17 \%$ of travelers made over 5 trips (these were mainly athletes that travel to practice sport at an amateur level), while the average is 3.8 trips per year.

According to the Econstat Observatory, $26.7 \%$ of sports tourists travel abroad, while the remaining $73 \%$ stay in Italy. As regards to the type of disciplines practiced, winter sports are in first place in this ranking (27\% of trips), followed by soccer (17\%), martial arts $(8.7 \%)$, water sports $(8.1 \%)$ and cycling (7.6\%). In terms of passive sports tourism, soccer moves $40 \%$ of sports travelers.

\section{Synergies between sport and tourism to enhance the local development of a territory}

In light of economic opportunities that the tourist industry can have especially in the global crisis (see $\S .2 .1$ ), improving the competitiveness of tourism is essential for strengthening this sector in sight of dynamic and sustainable growth. To achieve this, the importance of developing the following is widely acknowledged: innovation in tourism, enhancing the quality of services, improving professional skills in this sector, attempting to solve the problem of demand seasonality and diversifying tourism options (Eurostat, 2012).

The tourism sector is an important tool for local business development since tourism companies are, to a large extent, small and medium-sized firms. Sports tourism also has important synergies with local arts and crafts, which can help to preserve the cultural heritage and to develop local economies. One way to try to contribute to the diversification of tourism options is by encouraging the flow of tourists to go through the "mise en valeur" of "thematic" tourism products.

The synergies that can be created among several segments of tourism products may in fact encourage tourist promotion and visibility by including the entire tourist territorial heritage in its numerous aspects: cultural heritage (including cultural itineraries), protected natural sites, health and well-being tourism (including the spa tourism), the wine tasting, historical, religious and sports tourism, rural tourism, as well as the heritage of industrial archaeology of which many areas and regions are rich.

In recent years, the combination of endogenous resources of a territory with specific sports activities has emerged as a strategic tool: some sports have strong tourist peculiarities. Consider for example alpine skiing, cross-country skiing, sailing, cycling, paragliding, trekking, horse riding, etc. However, any sport can contribute to the development of a tourist "need". For example, traditional activities are "adapted" to new consumer needs. Such as the marathons that take place in beautiful and exotic places or in the desert - like in the case of the "Marathon des Sables" which is held in Morocco - where people feel like heroes since the race takes place in extreme conditions. Even winter sports (cross-country skiing, downhill skiing, snowboarding, freestyle, etc.) are important tools for the economic development of several mountain communities, often isolated and very poor before the boom of tourism industry.

Physical and sports activities carried out in a natural environment (en plein air) (ECOE, 2012) have gained increasing importance in recent years, becoming a development and enhancement tool for the 
territory, with a particular attention to the environmental sustainability. Sports can be functional for the promotion and eco-compatible development of a local context. Its diffusion has been enhanced within a strategic territorial promotion by local authorities, which have given great importance to tourism. Some regions in Italy and abroad have shown a great commitment to boost their territories through sports by building, for example, sports theme parks, such as golf courses, equestrian trails and parks on the coast or marinas for sailing enthusiasts.

There are many strategies to enhance a local territory, mainly by implementing specific infrastructures for sports in synergy with typical endogenous resources of the local context. For example, in recent years a number of initiatives have been launched centered on the strategic combination between sport, tourism, and traditional products. Examples of this include, cycling routes, and pilgrimage routes, such as the "Via Francigena" crossing Tuscany, Emilia Romagna, Lazio and Umbria or the Pilgrim's way to Santiago de Compostela in Spain, which can be travelled on foot or by bike. The dynamic created by the "experience" of physical practice matched with the enjoyment of tourism services within the territory (holiday cottages, gastronomic routes, etc.), acts as a catalyst for local development and tourism by providing attractive activities and services.

However, for the process of valorization through sports tourism development to be successful, it is important to analyze the potential attractiveness of the place towards athletes, tourists, visitors, new residents, etc., in order to ensure the satisfaction of these people with an experiential perspective.

The competition between various territories, "theatres" of sports opportunities, implies that the stakeholders who are responsible for promoting the place (city marketers, local authorities, municipalities, hotels, etc.) have to:

- connect the tourism opportunities, specifically linked to sports, with the opportunities of the territory,

- contribute to the creation and enhancement of a territorial sports opportunity.

This approach requires a variety of tools aimed at enhancing the potential attractiveness of a place by entering sports enterprises, local authorities, hotels, tour operators, etc. in systems that allow effective management of relations with the market. A proper territorial promotion strategy through sports should not be only designed to induce a potential visitor to "buy" the services offered within a specific territory (events, sport, etc.), but it should also establish a close relationship between customers (tourists, visitors) and local stakeholders (residents, institutions, local authorities, service providers, tour operators, etc.) (Wasche \& Woll, 2010) (Figure 6).

It is also important to implement a critical analysis of strengths and weaknesses, threats and opportunities. Based on this information, it will be possible to define a scenario on which to engage improvement measures to be implemented.

The purposes of a strategy to enhance and develop a local territory with a content of sports tourism can therefore be specified in the:

- promotion of local growth processes that combine economic and employment development with the preservation and enhancement of sport heritage, environment, and local products,

- widespread and non-selective effects (to ensure the development of the entire territory, not just in some places),

- exploitation of skills in the local system (institutional facilities, sports facilities, artificial environment, natural resources, knowledge and expertise embedded in the local context),

- perceptible and attractive visibility towards outside investors, due to the local vocation or distinctive connotation (single event, sporting event, individual sports).

The increase in value of a territory through the promotion of sports tourism should be addressed on one hand to promote activities that distinguish a specific local context (natural resources, typical products, sports, cultural, gastronomic activities, museum, etc.) and, on the other hand, to attract potential users. 


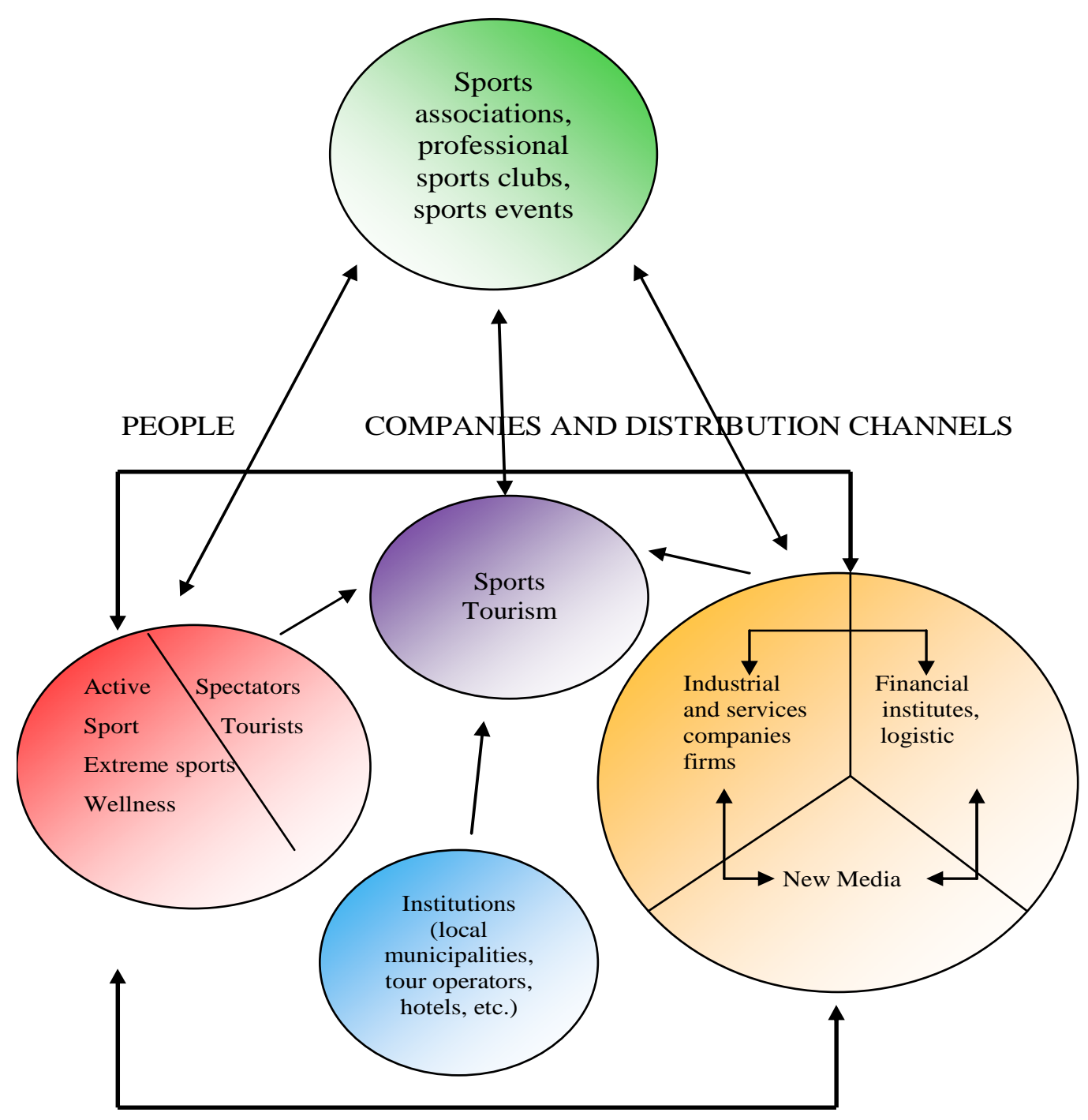

Figure 6. The system of relationships among stakeholders for promoting a territory through sports tourism activities Source: Adapted from Zagnoli, Radicchi, 2011

Stakeholders who are responsible for implementing a local development strategy should first ask which target (tourists, amateur athletes, spectators, etc.) they intend to provide their services to, and which needs must be met.

There are different segments of users on the basis of which differentiated sports offerings have to be designed. It is necessary to determine which sports are more attractive and which categories of sporting individuals are to be attracted (active sports, extreme sports, wellness, etc.).

The first step involves the identification and segmentation of users, that is, the splitting of the needs of people in multiple targets, so that they will be heterogeneous from each other, but homogeneous within each target group. The usefulness of a segmentation strategy depends on whether the demand for a certain product/service is not homogeneous and whether each individual user has its own specific requirements and special needs.

Demand segmentation is propaedeutic to the forecast analysis of the market and it allows an effective link with the decisions concerning the area's long-term development strategy. The primary goal is to identify the "profiles" for each user group taken into account. The segments can be grouped on the basis of several criteria: consumer behaviors and patterns of information and decision typical for each group. 
As regards the provision of services, on one hand it is necessary to identify a single decision-making centre to which aims, policies, choices relating to tourist complex systems would be reported, on the other hand it is necessary to analyze the strategic choices of the stakeholders involved in the process of marketing. The stakeholders would collaborate in the implementation of a sports tourism product through a network of relationships in which each partner has a specific role and pursues its own goals. Each stakeholder would help to "stage" the sports tourist product both in its core service (practice, equipment supply, choice and preparation of sports facilities, etc.) and its additional services such as hospitality, logistics, security, promotion of events and collateral activities that can be undertaken in a specific place.

Crucial in this regard is the role played by new multimedia and interactive tools, primarily the Internet and social media. Contemporary tourists, even in the light of low access costs, tend to use new technologies not only to organize their travel, but also to obtain information about a destination, for example, through geolocation based social networks and "augmented reality" which match the mobile communication with information related to specific places and activities (shops, restaurants, events, museums, etc.). It is important to remember that Web 2.0 tools allow sports tourism companies to amplify "word of mouth" effect by exchanging ideas and comments about products, services, experiences on websites, blogs, and social networks (Zagnoli \& Radicchi, 2011).

\section{REFERENCES}

Apostolopoulos, Y., Leivadi, S., \& Yannakis, A. (1996). The Sociology of Tourism. London: Routledge.

Brunetti, F. (1999). Il turismo sulla via della qualità /Tourism on the way of quality/. Padova: Cedam.

Crompton, J.L. (1979). Motivation for pleasure vacation. Annals of Tourism Research, 6, 409-424.

D’Allara, G. (1990). Perché le persone vanno in vacanza /Why do people go on holiday/. In D'Allara, G., Mitografia /Mithography/. Milano: Franco Angeli.

European Confederation of Outdoor Employees (ECOE) (2010). Defining the Outdoor. Retrieved February 8, 2011, from: http://www.ec-oe.eu

Forlani, F. (2005). Marketing, Esperienze e Territorio /Marketing, Experiences and Territory/. Doctoral Thesis. Genova: Università degli Studi di Genova.

Gibson, H. (1998). Active Sport Tourism: Who Participates?. Leisure Studies, 17(2), 155-170.

Hallman, K., Feiler, S., Muller, S., Breuer, C. (2012). The interrelationship between sports activities and the perceived winter sport experience. Journal of Sport\&Tourism, 17(2), 145-163.

Hautbois, C., Desbordes, M. (2008). Sport et Marketing Public. Paris : Economica.

Kotler, P., Bowen, J., Makens, J. (2003). Marketing del turismo /Tourism Marketing/. Milano: McGraw-Hill.

Kurtzman, J., Zauhar, J. (2005). Sport Tourism consumer motivations. Journal of Sport\&Tourism, 10(1), 21-31.

Mereu, A. (2005). La motivazione al turismo /The motivation for tourism/. Retrieved March 22, 2012, from: http://www.humantrainer.com

Murdy, J., Yannakis, A., Shuart J. (1999). The perceived impacts of tourism: economic, environmental and sociocultural influences of tourism on the host community. In G. Kyle (Ed.), Proceedings of NERR Symposium. Penn State University, April.

Nordin, S. (2005). Tourism of tomorrow: travel trends and forecasts of change. European Tourism Research Institute.

Pencarelli, T., Forlani F. (2006). Il marketing dei prodotti tipici nella prospettiva dell'economia delle esperienze IMarketing of typical products in the perspective of the experience economy/. Proceedings of International Congress "Le tendenze del marketing", Venezia: Università Cà Foscari, 20-21 Gennaio.

Pigeassou, C. (1997). Sport Tourism consumer motivations. Journal of Sport\&Tourism, 4(3), 18-31.

Ponticelli, B. (2006). La Motivazione al Turismo /Motivation for Tourism/. Retrieved March 10, 2012, from: http://www.psicolab.net

Radicchi, E., Zagnoli, P. (2008). Lo sport come veicolo di marketing esperienziale: tipologie di esperienza reale e virtuale /Sports as an experience marketing tool: typologies of real and virtual experiences/. Mercati e Competitività, 4/Dicembre, 101-125.

Radicchi, E. (2012). Megaeventos deportivos y creación de valor para las economías anfitrionas /Major Sports Events and value creation for the host economy/. In R. Llopis Goig (Ed.), Megaeventos Deportivos. Perspectivas Científicas y 
Estudios de Caso /Major Sports Events. Scientific Perspectives and Case Studies/ (pp. 25-51). Barcelona: Editorial UOC.

Russo, P. (2004). Sport e Società /Sport and Society/. Roma: Carocci.

Savelli, A. (1992). Sociologia del turismo /Sociology of Tourism/. Milano: Franco Angeli.

Standeven, J., De Knop, P. (1999). Sport Tourism. Leeds: Human Kinetics Europe.

Tamma, M. (2002). Destination management: gestire prodotti e sistemi locali di offerta /Destination management: managing products and local systems of offer/. In M. Franch (Ed.), Destination management. Governare il turismo tra locale e globale /Destination management. Tourism management between local and global/. Torino: Giappichelli.

United Nations World Tourism Organization (UNWTO) (2011). Tourism Highlights.

United Nations World Tourism Organization (UNWTO) (2012). World Tourism Barometer, 10/March.

Varaldo, R. (2002). L'industria del tempo libero: profili e prospettive /Leisure time industry: state of the art and perspectives/. In Resciniti, R. (Ed.), Economia e Marketing del tempo libero /Leisure Economics and Marketing/. Milano: Franco Angeli, 41-55.

Walker, G.J., Hinch, T., Higham, J. (2010). Athletes as tourists: the role of mode of experience and achievement orientation. Journal of Sport\&Tourism, 15(4), 287-305.

Wasche, H., Woll, A. (2010). Regional Sport Tourism Networks: a conceptual framework. Journal of Sport\&Tourism, 15(3), 191-214.

Weed, M., Bull, C. (2004). Sport Tourism. Participants, policy and providers. Oxford-MA: Elsevier.

World Tourism \& Travel Council (WTTC) (2012). Travel\&Tourism. Economic Impact.

Zagnoli, P., Radicchi, E. (2011). Sport Marketing e Nuovi Media /Sport Marketing and New Media/. Milano: Franco Angeli.

\section{AUTHOR'S ADDRESS: $\quad$ Elena Radicchi}

Laboratorio di management dello Sport

University of Florence

Viale Morgagni 63

Florence, Italy

Email: e.radicchi@unifi.it 